\title{
THE DEVELOPMENT OF TRADING NETWORKS AMONG SPATIALLY SEPARATED TRADERS AS A PROCESS OF PROTO-COALITION FORMATION: THE KULA TRADE
}

\author{
Bernard GROFMAN \\ University of California, Irvine * \\ Janet LANDA \\ York University**
}

Our aim in this paper is to look at graph-theoretic and coalition-formation approaches to the development of exchange networks among spatially separated traders. In particular, we shall show:

(1) That decentralized trading structures involving bilateral trading with left-hand and righthand neighbors in a connected ring can, for a certain specified spatial arrangement of traders, be more efficient in minimizing total transportation costs of goods than a centralized market-trading structure; and

(2) That an adaptation of a model of sequential proto-coalition formation proposed by Grofman (1982) can be used to predict trade linkages among traders in the Kula ring of the Massing region of Papua New Guinea and to account for the development of the inner ring structure.

We shall also briefly discuss how graph theory can be used as a tool to explicate the underlying market structure of a given network of traders.

\section{Introduction}

Stateless tribal societies in Papua New Guinea and elsewhere in Melanesia are characterized by a system of recurrent gift exchanges between pairs of partners connected in complex networks. Of these many gift-exchange systems, the most famous in anthropological litera-

* School of Social Sciences, University of California Irvine CA 92717, U.S.A.

** Department of Economics, York University, 4700 Keele St., Downsviews, Ontario, Canada.

$\dagger$ This research was partially supported by NSF Grant No. SES 80-07915, Program in Political Science. We are indebted to Donna Dill and other staff of the Word Processing Center, School of Social Sciences, UCI, and to Sue Pursche for the typing of this manuscript and the preparation of the accompanying figures and tables and for proofreading the manuscript. We also wish to acknowledge the helpful assistance of Guillermo Owen. 
ture is the Kula Ring, which is described in great detail by Malinowski (1922). Subsequent work by anthropologists such as Mauss (1954), Uberoi (1971), Belshaw (1965), Sahlins (1965), and Dalton (1978), among others, have attempted to explain the Kula gift-exchange system in terms of its role in creating friendly political alliances among potentially hostile neighboring tribes so as to facilitate intertribal commercial trade. The view that Kula gift exchange creates political order which facilitated intertribal trade while explaining one major puzzle of the Kula Ring leaves unanswered two other Kula puzzles not explained by anthropologists nor by anyone else:

(1) Why is the Kula trade organized in the form of a ring of trading partners; and

(2) Why in the Kula Ring are there two different kinds of Kula cermonial objects perpetually circulating in opposite directions among the ring of partners?

Landa (1980) has provided an economic explanation of these two enigmatic aspects of the Kula Ring, drawing on property rights-public choice theory and the economics of signalling. In the absence of a central marketplace, the ring structure of Kula trade is an institutional arrangement which economizes on trading costs (transportation and transaction costs) of organizing trade in $N$-spatially separated markets: each Kula trader needs to visit only two adjacent markets in order to acquire all traded goods when $N$-markets are connected together in a ring. This two-adjacent-market system can be viable only if all Kula partners abide by the rules of the Kula game (i.e., giving, receiving, and passing on the Kula gifts). The two different Kula gift objects, circulating in opposite directions among the connected chain of Kula partners, is an efficient signalling and monitoring device for the enforcement of the rules of the Kula game.

In explaining the two Kula puzzles, Landa also has provided a theory of the origins of the Kula Ring: The Kula Ring emerged by an "invisible hand process": the structural effects of each Kula trader, establishing two pair-wise Kula partnerships with neighboring traders, located on a ring of islands, generate a ring structure of Kula partnerships. The invisible hand process is, in effect, an entrepreneurial process in which each Kula trader perceives opportunities for making a profit by engaging in arbitrage between adjacent markets and seizes the 
opportunities by linking up a set of all submarkets. ${ }^{1}$ In this way, the entrepreneurial process will ensure that all $N$-spatially separated markets, located in a circular pattern, will eventually be linked up to form a ring of markets. ${ }^{2}$

Our aim in this paper, which is an extension of Landa's work on the Kula Ring, is to look at graph-theoretic and coalition-formation approaches to the development of exchange networks among spatially separated Kula traders. In particular, we shall show (1) that a decentralized trading structure involving bilateral trading with left-hand and right-hand neighbors in a connected ring can, for certain specified spatial arrangement of traders, be more efficient in minimizing total transportation costs of goods than a centralized marketplace trading structure; and (2) that an adaptation of a model of sequential protocoalition formation proposed by Grofman (1982) can be used to predict the exact sequence of the development of the Kula Ring decentralized trading network. We shall also briefly discuss how graph theory can be used as a tool to explicate the underlying market structure of a given network of Kula traders. We begin this paper with a review of some of the essential facts about the Kula Ring and the environmental setting within which it operates.

\section{The Kula Ring and its environmental setting}

The Kula Ring is a system of gift exchange carried on between six different East Papua Melanesian tribal groups who inhabit a ring of islands, lying off the southeastern extremity of Papua New Guinea, in the region of Massim. ${ }^{3}$ Each "Kula community" defined by Malinowski as "a community that makes overseas Kula trade as an independent unit" (p. 102), makes about two expeditions overseas every year. The ring of "Kula islands", the various "Kula communities", and the six tribal groups participating in the Kula Ring are shown in Map 1, with distances among the various islands shown in Table 1. These tribal

1 The Austrian theory of entrepreneurship particularly associated with Kirzner (1973) emphasizes this aspect of the entrepreneurial process.

2 Littlechild and Owen (1980) use an Austrian theory of the entrepreneurial process to show how in abstract spatially separated markets that entrepreneurial activities result in markets being linked together

${ }^{3}$ For details of the Kula Ring and its environment, see Landa (1980, especially the January 1982 (revised version). 
societies are predominately matrilineal and clan-based societies in which political and economic power in each village is vested in the hands of chicfs, as in the case of the Trobriand islands, or in the hands of village elders, headmen, or "Big-men". Because these tribal societies lack central government, they are what Dalton calls "stateless societies". It is among these stateless tribal societies in the Massim region that the Kula gift-exchange system was evolved as a way of creating friendly political alliances, which in turn facilitated interisland, intertribal trade; in the pre-Kula days, intertribal raiding and warfare were common occurrences and cannibalism was practiced by the Dobuan islanders.

Intertribal commercial exchange presupposes specialization and divi-

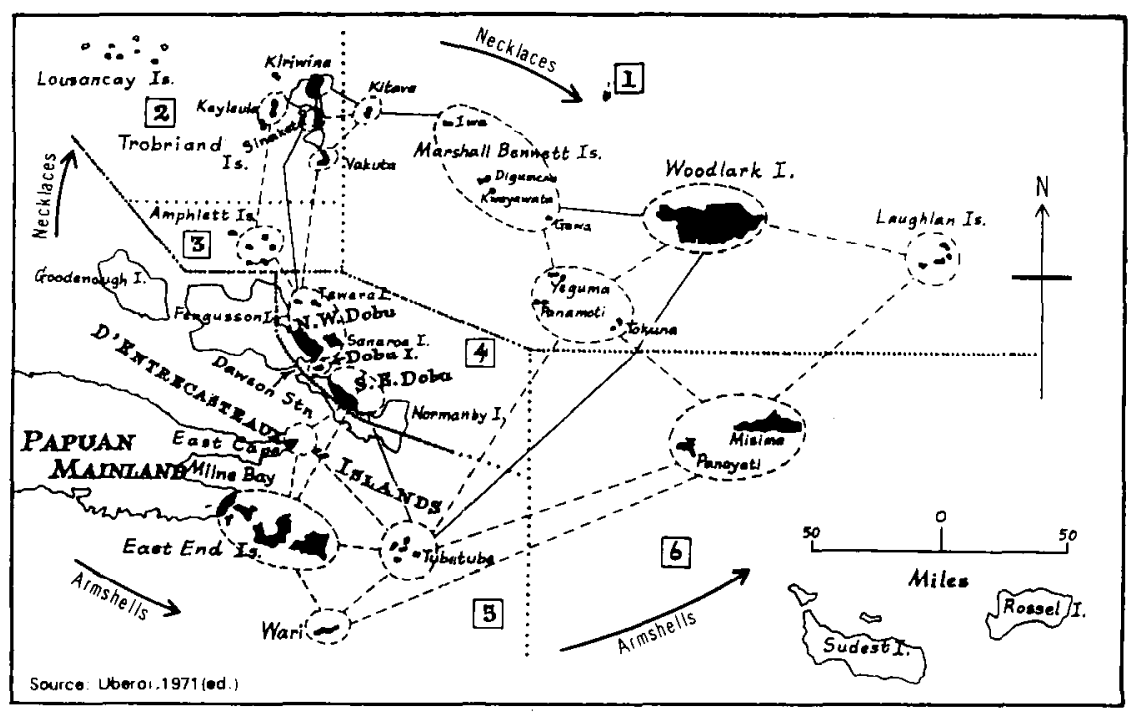

Map 1.

Kula Islands, Kula communities, ${ }^{*}$ and tribes ** in the Kula Ring.

Source: slightly modified from Uberoi (1971).

* Kula communities are circled in the map.

** Tribal communities in the Kula Ring:

1. The East Branch of the Northern Massim group;

2. Trobrianders;

3. Amphlett Islanders;

4. Dobuans;

5. The West branch of the Southern Massim group;

6. The East branch of the Southern Massim group.

The "Inner Kula Ring".

..... The "Outer Kula Ring". 
sion of labor among the various Kula communities, which, in turn, reflect the underlying differences in resource endowment. A short list of the main products of six Kula islands engaged in intertribal commercial trade underlines the mutual dependence on each other's agricultural and manufactured products (Table 2). All of these islands except Amphlett are in the inner Kula Ring, the main circuit of the Kula trade. Underlying differences in resource endowment makes commercial exchange mutually beneficial, and Kula partnerships make it possible for potentially hostile tribes to engage in commercial trade. In terms of the movement of traded goods, nondurables such as sago circulate over short distances of the Kula Ring while durable goods like pots and canoes circulate over large portions of the Kula Ring. With Kula traders establishing partnerships with traders in adjacent markets, opportunities for middleman entrepreneurship arose. Malinowski provided examples of middlemen from Sinaketa (in the Trobriands) making profits from reselling goods to traders in N.W. Dobu. ${ }^{4}$

It is the opportunities for profit-making via intermarket arbitrage that provided the entrepreneurial process of connecting hitherto unconnected markets via the political process of establishing Kula partnerships. As profit-making Kula traders, the incentive exists for each

Table 2

\begin{tabular}{lll}
\hline Islands & Products & Imported into \\
\hline Trobriand & $\begin{array}{l}\text { Yams, taro, sweet potatoes, } \\
\text { bananas, coconuts } \\
\text { Wooden bowls, combs, baskets, } \\
\text { lime plots } \\
\text { Pots }\end{array}$ & $\begin{array}{l}\text { Amphlett Is. } \\
\text { N.W. Dobu }\end{array}$ \\
Amphlett Islands & Sago & $\begin{array}{l}\text { Trobriand Is. } \\
\text { Marshall Bennett Is. } \\
\text { Woodlark Is., N.W. Dobu } \\
\text { Trobriand Is. }\end{array}$ \\
N.W. Dobu & Canoes & $\begin{array}{l}\text { Amphlett Is. } \\
\text { Tubetube }\end{array}$ \\
Bennett Is.) & Kula armshells & All islands in the Kula ring \\
Woodlark Is. & Canoes & $\begin{array}{l}\text { Tubetube } \\
\text { Gawa }\end{array}$ \\
Tubetube & Pots & Gawshall
\end{tabular}

4 Goods which circulate beyond two markets are desired by traders for purposes of potential resale. Hence, goods may become available from nearest neighbor traders even though not produced on that island. 
trader to economize on total trading costs which consist of transportation and transaction costs. In a world of $N$-spatially separated markets, transportation costs comprise a significant portion of total trading costs. We shall show that a ring structure of trading networks, under certain specified conditions, is Pareto-superior to a central marketplace trading structure for economizing on transportation costs.

\section{Centralized versus decentralized trade structures}

Consider a set of geographically dispersed traders arranged in a circular structure as if around some perimeter (see Figure 1). It might appear obvious that efficient trade relationships call for the creation of a central market at point $O$, the circle's origin, thus creating a (Kula) star structure. Actually, the situation is more complex. Let us initially posit zero transaction costs involved in the handling of trade goods by intermediaries. Rather, the total costs of trade shall be assumed to be a linear function of the distance over which goods must travel from point of origin to point of destination. If we have a central market $O$, the distance, $D_{c}$, over which any goods will travel from point of origin to point of destination is simply the radius of the circle. If we denote by $R$ the radius of the circle, we have

$D_{c}=2 r$.

Now, consider a pairwise trading network in the form of a ring in

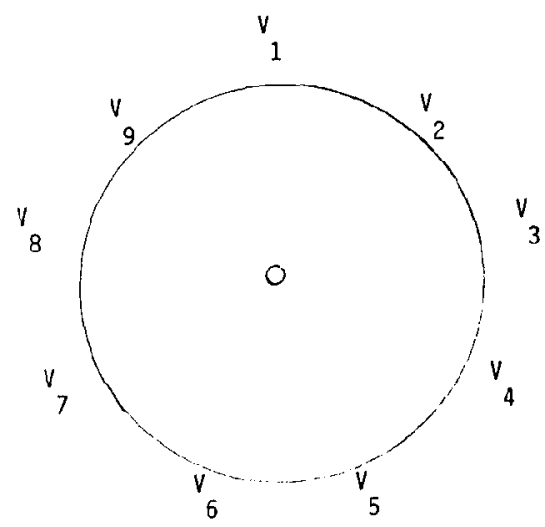

Figure 1. Circular dispersion of traders $(N=9)$. 
which trader $V_{i}$ trades only with his right-hand neighbor $V_{i+1}$, and with his left-hand neighbor $V_{i-1}$. To get a good from $V_{k}$ to $V_{k+1}$ we traverse the chords of the arcs from $V_{k}$ to $V_{k+1}, V_{k+1}$ to $V_{k+2}$, and $V_{k+l-1}$ to $V_{k+1}$. This distance may be reasonably well approximated as the arc of $\left\{V_{k}, V_{k+1}\right\}$ if the traders are close together. The maximum distance between any two traders is then approximately $\pi R$, since any good may be shipped by either a left-hand or a right-hand route. Moreover, if traders (and trade goods) are uniformly distributed over the circumference of the circle, then the expected travel distance for any good which is passed via a sequence of pairwise trades, which we shall denote $D_{P}$, is approximaled by

$D_{P}=\frac{\pi R}{2}$.

It is apparent that $\pi R / 2<2 R$; hence we seem to have demonstrated that, for a circular arrangement of traders, a sequence of pairwise trades is preferable to a central market. However, our result hinged on the assumption of a uniform distribution of traders around the circumference which permitted us to approximate the average travel distance as simply $\pi R / 2$. If $N$, the number of traders, is small, then using the arc length instead of the sum of the chord lengths is misleading. But since the sum of the chord lengths is always less than the arc length, our result is only strengthened. A more serious problem is that, in looking at the average trade, we have failed to look at incentives for any given trade. It may be that for any given trader, costs of transport rise more than linearly with distance - because of uncertainties in navigation, inadequate food storage for long trips, etc. In such a case, it may be that any given trader will prefer pairwise trade with his neighbor to a trip to the central market at $\mathrm{O}$ only if the distance to his neighbor is less than $R$. We show in Figure 2 that this condition is satisfied, for a symmetric distribution of traders, if $N \geqslant 6$, since a $60^{\circ}$ angle gives us an equilateral triangle with chord length (distance between traders) equal to $R$.

If we use arc lengths instead of chords, it is easy to see that

$$
\frac{2 \pi R}{N}<R \text { iff } N>6 .
$$

On the hasis of these results, we would assert 


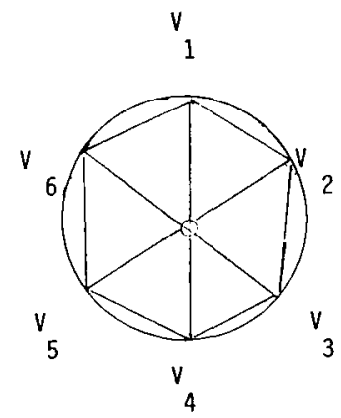

Figure 2. Hexagonal trade pattern $(N=6)$.

Result 1. For $N \geqslant 6$, for a uniform distribution of traders in a circular pattern, a pairwise trading pattern (ring) is more efficient in minimizing total transport costs than is a centralized market.

It is straightforward to generalize this result to the case of an elliptical dispersion of traders. The circumference of an ellipse is $\pi(a+b)$, where $a$ and $b$ are the radii of the ellipse's major and minor axes. If we let $a<b$, then the minimal distance from any point to the ellipse's center of gravity is simply $a$. Hence,

Result 2. For a symmetric distribution of traders around the perimeter of an ellipse, for all traders to prefer to trade with their neighbor rather than at a central market located at the center of gravity of the ellipse, it is sufficient to have

$\frac{\pi(a+b)}{N}<a$,

and necessary to have

$$
\frac{\pi(a+b)}{N}<b \text {. }
$$

We may rewrite equation (4) as

$$
\frac{\pi}{N-\pi}<\frac{a}{b}
$$

and equation (5) as

$$
\frac{\pi}{N-\pi}<\frac{b}{a} \text {. }
$$


For example, if $a / b=\frac{1}{2}$, for a symmetric distribution of traders around the perimeter of the ellipse, for pairwise trade to be preferred to a central market it is sufficient to have $N \geqslant 10$. This is not a necessary condition since no trader may be located at the minimum distance from the ellipse' center of gravity. A necessary condition is given by equation (7), from which we have $N \geqslant 7$.

Consider a matrix, which we shall denote $n_{2}$, indicating with 1's each trading partner's two nearest neighbors, with zeroes elsewhere in the matrix. It is straightforward to demonstrate the following:

Result 3. A sufficient condition for the transport-distance minimizing structure for a given trading network to be a ring is that $N_{2}$ be both symmetric and connected.

If $N_{2}$ is symmetric but not connected, then it can be decomposed into separate ring structures.

An oval pattern of spatial arrangement is shown in Map 2, which shows the location of the 11 trading partners (mostly island communities) in the inner Melanesian Kula ring which includes the Trobriand Islands, off the coast of Papua New Guinea. Trade among these islands is characterized by pairwise trading relationships with nearest neighbors which generate a connected ring of traders. Let us now look at the Kula
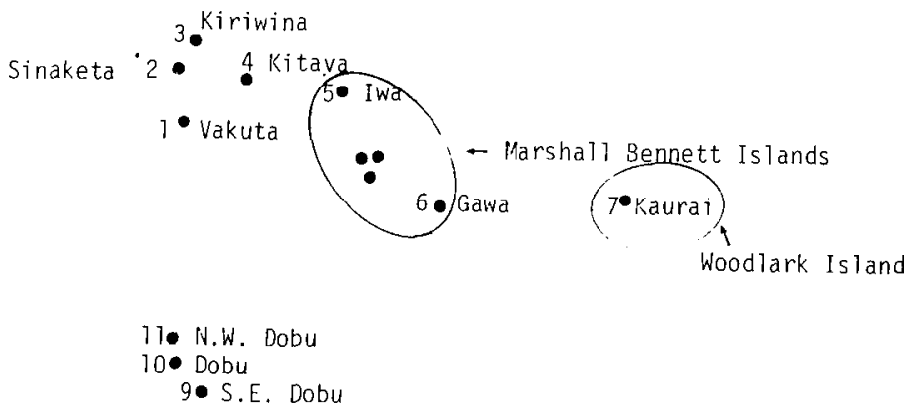

Map 2. 
trade in more detail to see if any of our above results, in particular, Result 3, are applicable.

\section{The emergence of the Kula Ring: Two-nearest-neighbor model}

There are two basic approaches to the specification of probable trade routes among spatially separated traders. One is based on the use of various optimal routing algorithms which treat this problem as one of finding the trading network which achieves an overall transport distance minimum for all commodity transfers (see e.g., Kaufmann and Faure 1968. especially Chapter 5). Such algorithms look for global optima. This is normatively useful but begs the question of whether a decentralized trading process based on individual trader decisions can be expected to give rise to global optimization.

A second approach is to look at the set of $K$ "nearest-neighbors" and to posit that each trader engages in trade with these nearest neighbors (for example, Irwin (1981) looks at a three-nearest-neighbor model of Kula trade). While this is not an unreasonable way to proceed, it fails to take into account that trade is a process of exchange: that $i$ wishes to trade with $j$ does not guarantee that $j$ wishes to trade with $i$, when there may be other alternative traders available with whom $j$ might deal.

We propose a third approach, one which posits the development of trade routes through a process of individual independent choices rather than positing a global search for overall efficiency, and one which looks at trade as a process of reciprocal choice of exchange partners. Because of the possibilities of middleman trade we may assume that all actors have goods which are desired in trade by all actors (see Table 2). Having shown that the decentralized ring structure is, under certain specified conditions, Pareto-superior to a central marketplace structure, we shall now attempt to provide a model of how the exact sequence of segments of the Kula Ring conceptually might have emerged; our model is based on two-nearest-neighbor "short-path-matrix" analysis.

We have shown in Table 1 a distance chart for the 11 trading partners in the central Melanesian Kula ring including the Trobriand islands (see Map 2). On the basis of the data in Table 1, we can readily construct $\mathrm{N}_{2}$ for this trading network (see Figure 3).

Figure 3 is not symmetric, though it is nearly so. $N_{2} \cap N_{2}^{t}$ indicates which choices of trade partners are reciprocated. We show $N_{2} \cap N_{2}^{t}$ in Figure 4. 


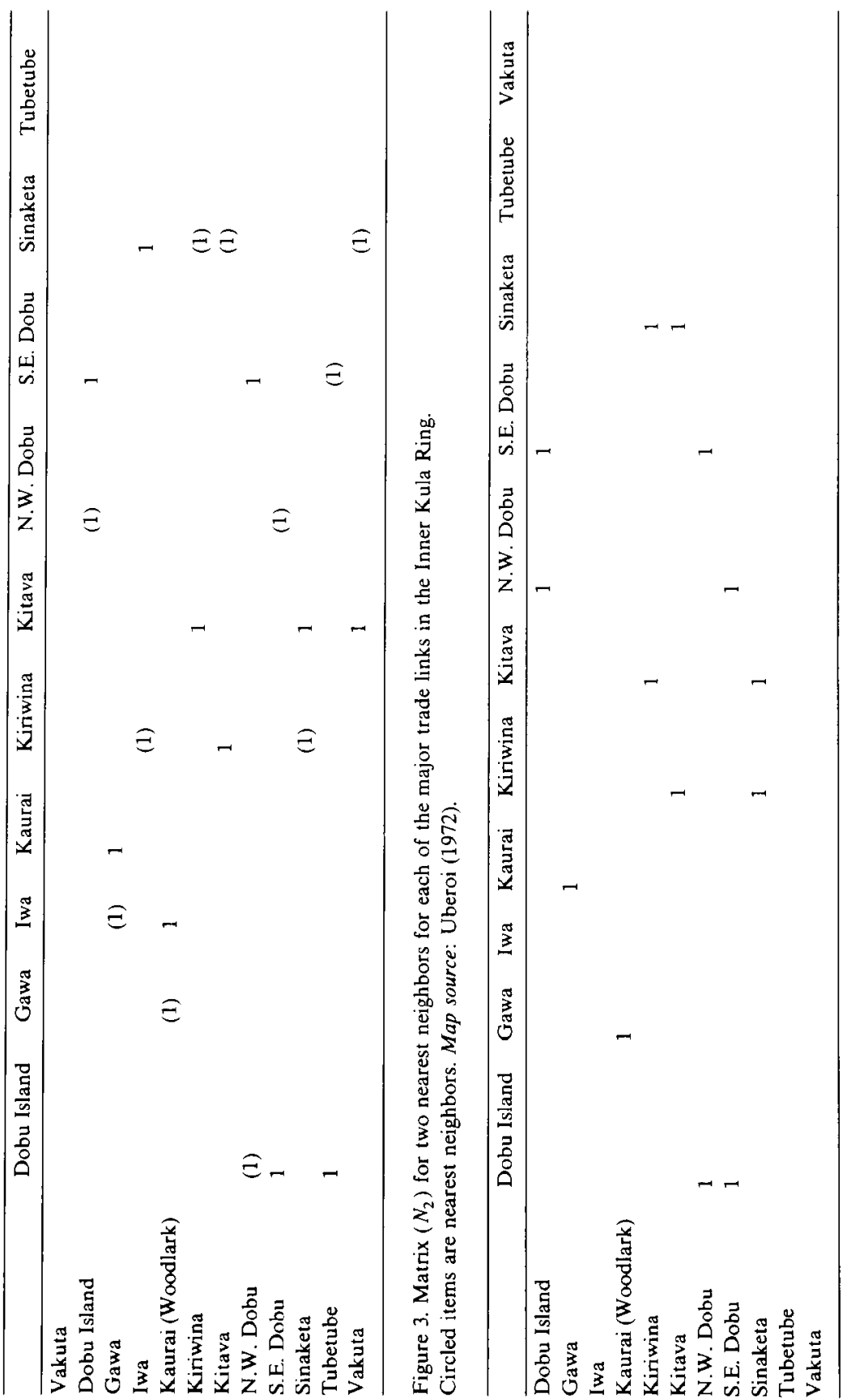

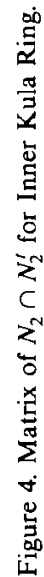




\begin{tabular}{lllllc} 
& Gawa & Iwa & Kaurai & Tubetube & Vakuta \\
\hline Gawa & 1 & 1 & $X$ & & 1 \\
Iwa & $\mathrm{X}$ & 1 & & 1 \\
Kaurai & 1 & 1 & & \\
Tubetube & 1 & 1 & & \\
Vakuta & & & & \\
\hline
\end{tabular}

Figure 5. Reduced matrix of two nearest neighbors for the five not yet saturated trading partners.

\section{Model I}

We may generate a trade structure based on the two nearest neighbors by an iterative process which takes into account reciprocal choice. In this first simple model, which we shall label Model I, we shall consider any trader with two trade partners as saturated. This leaves Gawa, Iwa, Kaurai, Tubetube, and Vakuta as still in need of additional trading partners.

Now let us look at the matrix of two nearest neighbors, confining ourselves to the reduced set of nonsaturated trading actors. (For Gawa and Kaurai we shall actually look only at the one nearest neighbor since each already has one trading partner.)

Now we can repeat our earlier tactic and look at the intersection of the matrix in Figure 5 with its own transpose. This gives us Figure 6.

Now Gawa and Iwa are saturated, leaving Tubetube in need of two trading partners and Kaurai and Vakuta each in need of one.

Repeating the process, we obtain Figure 7. We shall not bother to show the intersection of this matrix and its transpose. It is apparent that Iwa is now saturated and Kaurai and Vakuta will trade (and be fully saturated) but that Tubetube has no trading partners. At this point the process is complete, but the resultant structure is not a ring;

\begin{tabular}{llllll}
\hline & Gawa & Iwa & Kaurai & Tubetube & Vakuta \\
\hline Gawa & 1 & 1 & $\mathrm{X}$ & \\
Iwa & $\mathrm{X}$ & & & 1 \\
Kaurai & & & & \\
$\begin{array}{l}\text { Tubetube } \\
\text { Vakuta }\end{array}$ & & 1 & & & \\
\hline
\end{tabular}

Figure 6. Intersection of the matrix of Figure 5 with its own transpose. 


\begin{tabular}{|c|c|c|c|}
\hline & Kaurai & Tubetube & Vakuta \\
\hline \multicolumn{4}{|l|}{ Kaurai } \\
\hline Tubetube & 1 & & 1 \\
\hline Vakuta & 1 & & \\
\hline
\end{tabular}

Figure 7. Reduced matrix of two ncarcst neighbors for the three trading partners who are not as yet saturated.

rather it is several rings and one singleton. ${ }^{5}$ Kiriwina, Kitava, and Sinaketa form a self-enclosed triplet as do N.W. Dobu, S.E. Dobu, and Dobu Island. Also, Vakuta, Iwa, Gawa, and Kaurai form a ring. Tubetube is, however, an isolate structure. The structure generated by this sequence can be depicted as below.

$$
\begin{array}{ll}
2 \leftrightarrow 3 \leftrightarrow 4 & 7 \leftrightarrow 5 \leftrightarrow 6 \leftrightarrow 1 \\
9 \leftrightarrow 10 \leftrightarrow 11 & 8 .
\end{array}
$$

We could proceed to consider the structure that would be generated if we assumed that three trading links were necded to produce saturation, or the structure that would be generated by practical choices in a three-nearest-neighbor model [as has been done by Irwin (1981)], but we shall instead consider a closely related alternative approach which is a variant of a sequential model of proto-coalition formation proposed in Grofman (1982).

\section{A dynamic model of proto-coalition formation applied to the develop- ment of trading linkages in the Kula Islands' Inner Kula Ring}

\section{Model II}

The basic idea of the second model we shall propose is quite simple, and similar to the two-nearest-neighbor model we offered in the previous section of the paper. We begin with a nearest neighbor matrix, $N_{1}$. If $i$ is the nearest neighbor of $i$ and $j$ is also the nearest neighbor of $i$, then we posit that $i$ and $j$ become permanent trading partners. In other

\footnotetext{
${ }^{5}$ We would expect Vakuta to try to link to Sinaketa or Kitava. and Tubetube to try to link with S.E. Dobu and/or Dobu Island.
} 
words, we again required reciprocated choice for exchange to take place. Once having formed a proto-coalition, we posit that the members of this proto-coalition act as a unit, and the distance of traders to and from the proto-coalition is calculated as the distance to the proto-coalition's closest member. In effect, we are not requiring all actors in each proto-coalition to participate in the new combined proto-coalition but rather positing a segmentary coalition formation involving partially overlapping members. After an initial round of proto-coalition formation, we now look at a second stage in which some traders are singleton proto-coalitions while others are two-actor proto-coalitions. Again we generate a new proto-coalition wherever proto-coalition $I$ is the nearest neighbor of proto-coalition $J$ and vice versa. We continue in this process until all traders are connected. Unlike our first model, we do not assume that actors with two trading partners are saturated. Indeed, the concepts of saturation plays no role in this model. Grofman (1982) has proved the following result for a model essentially identical to that specified above, except that distance is treated as weighted distance to a proto-coalition center of gravity.

Result 4. For actors embedded in an N-dimensional space the protocoalition formation process described in Model II above must continue until all potential coalition members are included in a grand coalition; i.e, the process is such that at every stage of the process there must be at least one proto-coalition $K$ for which proto-coalition $K$ 's nearest neighbor has proto-coalition $K$ as its nearest neighbor.

It is straightforward to modify the proof in Grofman (1982) to obtain this result for the model in this paper in which distance is defined in terms of each proto-coalition's nearest neighbor.

Result 5 (due to Professor Philip Straffin, Department of Mathematics, Beloit College, personal communication April 1983). The proto-coalition process described in Model II above will generate the shortest distance routing path; i.e., even though it is based on pairwise choices, it will achieve global efficiency.

We shall demonstrate the application of this method to the 11 inner Kula Ring traders whose spatial relationships were shown in Table 1 and Map 2. To help in following the process, we have shown the sequence of proto-coalition formation on a map identical to Map 2.

What we observe at the end of six stages of this dynamic proto-coali- 
tion formation process are two large proto-coalitions. At stage 7 these two proto-coalitions would join, with N.W. Dobu (in the southern proto-coalition) trading with Vakuta (in the northern proto-coalition). At this point we would still not have a ring. Rather we would have the matrix shown in Figure 8.

This matrix is equivalent to the following disconnected graph

$1 \leftrightarrow 2 \leftrightarrow 3 \leftrightarrow 4 \leftrightarrow 5 \leftrightarrow 6 \leftrightarrow 7$

$11 \leftrightarrow 10 \leftrightarrow 9 \leftrightarrow 8$.

It is clear that we would obtain a ring structure if $1 \leftrightarrow 11$ and $7 \leftrightarrow 8$.

The next stage, stage 7 , of our proto-coalition process gives rise to the $(1,11)$ link-up, i.e., the string shown below.

$8 \leftrightarrow 9 \leftrightarrow 10 \leftrightarrow 11 \leftrightarrow 1 \leftrightarrow 2 \leftrightarrow 3 \leftrightarrow 4 \leftrightarrow 5 \leftrightarrow 6 \leftrightarrow 7$.

However, we still have only a string, not a ring. To generate the ring structure, Tubetube must go to sea (to Kaurai) or vice versa! There are

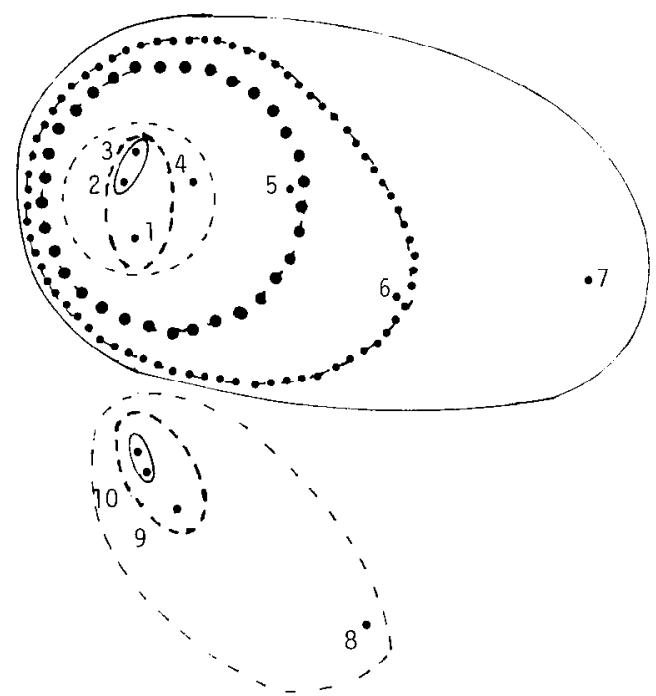

Map 3.

Stages of a dynamic model of proto-coalition (Grofman 1982) as applied to the major trade link in the inner Kula Ring (distances only approximate).

- Stage 1; - - -Stage 2; - - Stage 3; • • Stage 4; - . Stage 5; - Stage 6. 


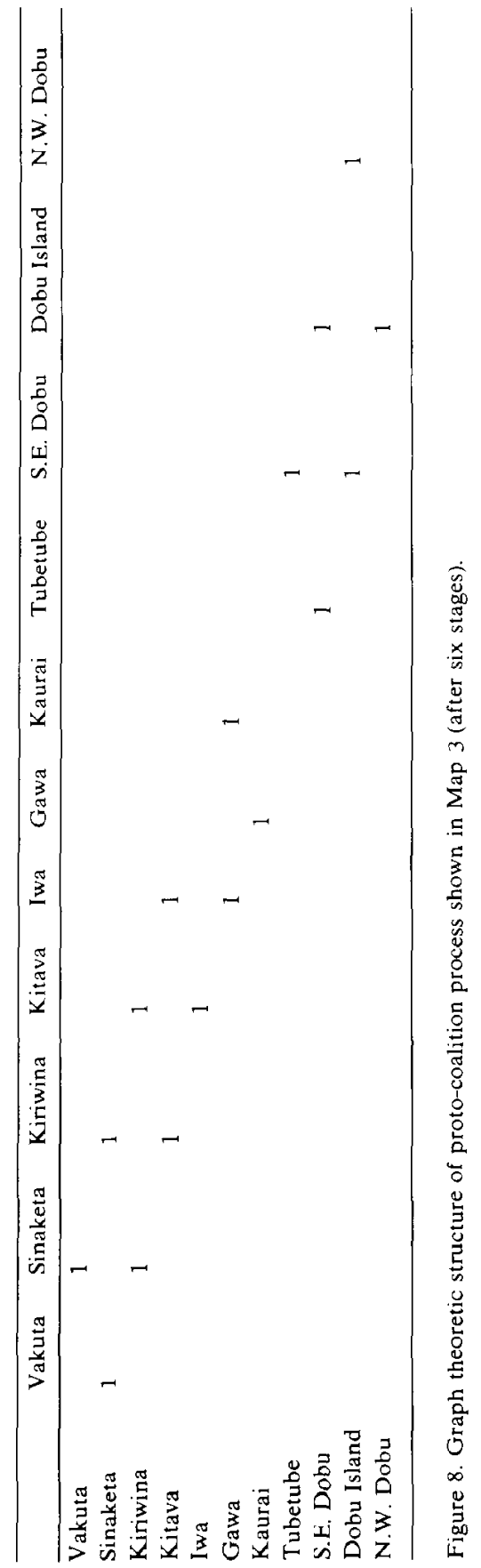


good economic reasons for Tubetube, in particular, to seek to connect up to the ring. Tubetube is a tiny volcanic island which is poor in natural resources. With the exception of clay pots and nose ornaments which Tubetube islanders manufacture for export, Tubetube has no traded goods of any major significance. Tubetube, however, is centrally located vis-à-vis communities in the Southern Massim region; its central location has been, for example, demonstrated by Irwin (1981). Tubetube seized the locational advantage by emerging as the specialized long-distance seafaring middlemen who travelled to foreign markets and organized foreign trade in Southern Massim, hence connecting up the Kula Ring. Trade between Kaurai and areas such as S.E. Dobu, Dobu Island, and Tubetube (or between Tubetube and areas such as Kaurai, Gawa and Iwa) takes place over a very long string of middlemen. By bridging the gap, Tubetube can offer goods (from Tubetube, S.E. Dobu, and Dobu Island) to Kaurai at a lower cost than that at which Kaurai could obtain those goods from these islands via the long and winding middleman chain if the string pattern was the only trading route. ${ }^{6}$ Similar reasoning applies for Woodlark Island (Kaurai). Moreover, as mentioned, these two islands have the strongest incentives for " bridging" the horseshoe gap (see Map 2), although Tubetube has additional economic incentives to do so.

\section{Conclusions}

In this paper, we have provided two theorems on decentralized trading structures. We have shown that, under certain conditions, the Kula Ring structure (the two-adjacent-market system) is Pareto-superior to the "Kula Star" structure (a central marketplace) in economizing on transportation costs. Having demonstrated that the Kula Ring structure is efficient in terms of reducing transportation costs, we then attempt to predict the exact sequence of the emergence of segments of the Kula Ring trading network, first by using the two-neighbors graph-theoretic

${ }^{6}$ In fact, Tubetube is a community of seafarers who regularly travel further distances by sea than traders from other islands (see Irwin, 1981). Our approach suggests a reason why, given the spatial arrangements of these islands, either Tubetube or Kaurai would have a reason to develop seafaring expertise. Tubetube, as mentioned in the text, has special additional reasons for emergence as a base for long distance sea faring middleman trade. 
model and then by use of a dynamic model of proto-coalition formation. The methodology we have proposed may be to include a wide variety of decentralized and partly decentralized gift-exchange networks in Papua New Guinea and elsewhere in Melanesia.

\section{References}

Belshaw, C.S.

1965 Traditional Exchange and Modern Markets, New Jersey: Prentice-Hall.

Dalton G.

1978 "The impact on colonization on aboriginal economies in stateless societies". In Research in Economic Anthropology. Vol. 1, 131-184.

Grofman, Bernard

1982 "A dynamic model of proto-coalition formation". Behavioral Science, February.

Irwin, Geoffrey

1981 "Archeology in the Kula Area". Paper delivered at the Kula Conference, University of Virginia, Junc 1-9.

Kaufmann, A. and R. Faure

1968 Introduction to Operations Research. New York: Academic Press.

Kirzner, L.

1973 Competition and Entrepreneurship. Chicago: University of Chicago Press.

Landa, Janet

1980 "Primitive Public Choice and Exchange: An Explanation of the Enigma of the Kula Ring". Paper delivered at the Annual Meeting of the Public Choice Society, March 14-16. 1980, San Francisco, CA; revised version. Institute for Policy Analysis, University of Toronto, Working Paper, No. 8123 (June, 1981) and third revised version, January 1982 forthcoming in International Revicw of Law and Economics, Vol. 3, December 1983.

Littlechild, S.C. and G. Owen

1980 "An Austrian model of the entrepreneurial market process". Journal of Economic Theory $361-379$.

Malinowski, Bronislaw

1922 Argonauts of the Western Pacific, London: Routledge (also Dutton and Company, 1961, paperback edition).

Mauss, Marcel

1954 The Gift, London: Routledge and Kegan Paul.

Sahlins, Marshall

1972 Stone Age Economics, Chicago: Aldine Atherton.

Uberoi, J.P.P. Singh

1971 Politics of the Kula Ring, Manchester: University Press. 